\title{
Crop host signatures reflected by co-association patterns of keystone Bacteria in the rhizosphere microbiota
}

\author{
Simon Lewin ${ }^{1}$, Davide Francioli ${ }^{1}$, Andreas Ulrich ${ }^{1}$ and Steffen Kolb ${ }^{1,2^{*}}$ (D)
}

\begin{abstract}
Background: The native crop bacterial microbiota of the rhizosphere is envisioned to be engineered for sustainable agriculture. This requires the identification of keystone rhizosphere Bacteria and an understanding on how these govern crop-specific microbiome assembly from soils. We identified the metabolically active bacterial microbiota (SSU RNA) inhabiting two compartments of the rhizosphere of wheat (Triticum aestivum L.), barley (Hordeum vulgare L.), rye (Secale cereale), and oilseed rape (Brassica napus L.) at different growth stages.

Results: Based on metabarcoding analysis the bacterial microbiota was shaped by the two rhizosphere compartments, i.e. close and distant. Thereby implying a different spatial extent of bacterial microbiota acquirement by the cereals species versus oilseed rape. We derived core microbiota of each crop species. Massilia (barley and wheat) and unclassified Chloroflexi of group 'KD4-96' (oilseed rape) were identified as keystone Bacteria by combining LEfSe biomarker and network analyses. Subsequently, differential associations between networks of each crop species' core microbiota revealed host plant-specific interconnections for specific genera, such as the unclassified Tepidisphaeraceae'WD2101 soil group'.

Conclusions: Our results provide keystone rhizosphere Bacteria derived from for crop hosts and revealed that cohort subnetworks and differential associations elucidated host species effect that was not evident from differential abundance of single bacterial genera enriched or unique to a specific plant host. Thus, we underline the importance of co-occurrence patterns within the rhizosphere microbiota that emerge in crop-specific microbiomes, which will be essential to modify native crop microbiomes for future agriculture and to develop effective bio-fertilizers.
\end{abstract}

Keywords: $16 \mathrm{~S}$ rRNA, Amplicon sequencing, Barley, Co-occurrence network, LEfSe, Oilseed rape, RNA, Rye, Wheat

\section{Background}

Crop plants are colonized by a microbiota. This symbiotic association constitutes a holobiont that responds jointly to environmental factors [1-3]. A systemic understanding of the crop bacterial microbiota and utilization of its plant-beneficial effects may allow for plant productions

\footnotetext{
*Correspondence: kolb@zalf.de

${ }^{1}$ Microbial Biogeochemistry, Research Area Landscape Functioning,

Leibniz Centre for Agricultural Landscape Research e.V. (ZALF),

Müncheberg, Germany

Full list of author information is available at the end of the article
}

systems that will be more resilient to climate change and may address sustainability concerns $[4,5]$. Current crop cultivars require nutrient fertilization and further agrochemicals to allow for stable and sufficient yields. However, agrochemical inputs lead eventually to an increasing environmental pollution and biodiversity losses $[6,7]$.

Specific interactions of crop rhizosphere microorganisms modulate and improve plant resilience against environmental stressors by (i) mobilization of plant nutrients, (ii) growth promotion through plant hormone synthesis, (iii) systemic or indirectly induced pathogenic resistance, and (iv) antagonistic effects on original author(s) and the source, provide a link to the Creative Commons licence, and indicate if changes were made. The images or other third party material in this article are included in the article's Creative Commons licence, unless indicated otherwise in a credit line to the material. If material is not included in the article's Creative Commons licence and your intended use is not permitted by statutory regulation or exceeds the permitted use, you will need to obtain permission directly from the copyright holder. To view a copy of this licence, visit http://creativecommons.org/licenses/by/4.0/. The Creative Commons Public Domain Dedication waiver (http://creativeco mmons.org/publicdomain/zero/1.0/) applies to the data made available in this article, unless otherwise stated in a credit line to the data. 
pathogens $[8,9]$. These specific interactions are realized by the diverse microbial species of the same crop microbiota. An important factor that supports microbial growth in the rhizosphere making it to a microbial biomass and activity hotspot adjacent to the soil is the release of rhizodeposits. These foster niche differentiation nearby the root [10] and fuel microbial growth [11, 12]

Differences in physicochemical soil characteristics have the strongest impact on the rhizosphere bacterial microbiota composition. They have been proven for plant species such as Arabidopsis thaliana [13, 14], Hordeum vulgare L. (barley) [15] and Triticum aestivum L. (wheat) $[16,17]$ but also for complex plant communities in grasslands [18]. Nonetheless, host plant-specific core bacterial microbiota can also be observed across different edaphic and climatic conditions $[16,17,19,20]$ and growth stages [21].

The effect of host identity on the assembly of the rhizosphere bacterial microbiota is considered to be most pronounced in domesticated plants and different between crop host species $[15,22]$. Monocotyledonous and dicotyledonous plants likely differentially shape the rhizosphere bacterial microbiota because of divergent root architecture and physiology [13, 23]. Plant host-specific acquirement of soil Bacteria in the rhizosphere of cereals can also be attributed to microbial functions [24, 25]. Plant host-specific acquired Bacteria may correlate with root secondary metabolite spectrum [25] which is often evolutionary conserved at the plant family level [26]. Hence, the comparison of crop species and their metabolic active rhizosphere bacterial microbiota is key to understand the plant host contribution to the bacterial microbiota assembly.

Previous studies compared host selection of the bacterial microbiota by crops, such as wheat, barley, maize, soybean, or oilseed rape in either glasshouse experiments or field trials. The rhizosphere bacterial microbiota of two or more crop species tend to share large fractions of microbial taxa [27]. Contrary, divergence at phylum level and overall composition have also been observed [15, 23, 24]. Moreover at a finer taxonomic resolution, Bacteria specific and essential to individual host crops have been recently identified [28-30]. To resolve such partially inconsistent observations regarding host-specificity of bacterial keystone taxa on the one hand and a frequent detection of many rhizosphere microbiota in different plant hosts requires an alternative and systematic assessment of their active bacterial members. These may be achieved by focusing on a core microbiota in comparative experimental studies and using the SSU RNA pool as an indicator for functionally relevant and active associations.
We suggest here to screen for host-specific Bacteria using linear discriminant analysis and estimating biological consistency and effect size [31]. Further permanent and conditional occupancy of Bacteria may have distinct ecological roles to the host [32] that we delineated using core microbiota inference [33]. Further co-occurrence network and hub node analyses are well suited to predict keystone Bacteria that directly and indirectly preserve microbiome structure [32].

Our study addressed the bacterial rhizosphere microbiota of four major crops grown widely in Europe and worldwide, i.e. wheat (Triticum aestivum L.), rye (Secale cereale L.), barley (Hordeum vulgare L.), and oilseed (Brassica napus L.). We compared the rhizosphere bacterial microbiota of single plant holobionts grown in pots and with the same agricultural soil. Two rhizosphere compartments (close, RZP; distant, RZS) were sampled to resolve niche partitioning of Bacteria in the rhizosphere [34]. Active Bacteria present among the rhizosphere microbiota were detected through the SSU RNA pool as a phylogenetic marker and proxy for activity [18, 35]. We focused on the temporal persistent Bacteria assuming a conserved symbiotic relationship and identified the hub Bacteria of individual crop host species and their direct cohort interactions partners by network comparisons to resolve differences between crop rhizosphere bacterial core microbiota irrespective of abundance.

We expected to detect rhizosphere bacterial microbiota of the three cereal crop species and oilseed rape that (a) exhibit diverging composition affected by individual plant host filtering and that (b) comprise bacterial biomarker taxa specific for each crop species within the host core microbiota. (c) We further expected that hub Bacteria occur among the core microbiota of each host, which foster the acquirement of unique cohort sub-networks and orchestrate differential associations as host-specific signatures.

\section{Methods \\ Experimental design and sampling}

A glasshouse experiment was conducted at Leibniz Centre for Agricultural Landscape Research (Müncheberg, Germany) with summer cultivars of wheat (Quintus), barley (Marthe), rye (Ovid), and oilseed rape (Campino) from May to July 2019. An arable soil was collected for planting during April 2019 near Prenzlau (Germany). The soil was air dried, sieved and homogenized. The soil texture was between medium loamy to medium silty sand (SI3/SU3) and the chemical characteristics are listed in Tables 1 and 2. Single plants in pots of 1.51 were grown in a randomized design. Each pot was adjusted to a soil density of $1.2 \mathrm{~g} \mathrm{l}^{-1}$ and initially watered to $60 \%$ field capacity. Seeds were 
Table 1 Bulk soil chemical properties

\begin{tabular}{llllllll}
\hline $\begin{array}{l}\mathrm{NH}_{4}^{-} \\
\mathbf{m g ~ g}^{-1} \text { soil }\end{array}$ & $\begin{array}{l}\mathrm{NO}_{3}^{-} \\
\mathbf{m g ~ g}^{-1} \text { soil }\end{array}$ & $\mathrm{pH}$ & $\begin{array}{l}\mathrm{C}_{\mathrm{t}} \\
\%\end{array}$ & $\begin{array}{l}\mathrm{N}_{\mathrm{t}} \\
\%\end{array}$ & $\begin{array}{l}\mathrm{S}_{\mathrm{t}} \\
\%\end{array}$ & $\begin{array}{l}\mathrm{TIC} \\
\%\end{array}$ \\
\hline 0.0008 & 0.0276 & 5.415 & 0.721 & 0.068 & 0.0118 & 0.013 \\
\hline
\end{tabular}

Table 2 Bulk soil chemical properties of plant available cations

\begin{tabular}{|c|c|c|c|c|c|}
\hline $\begin{array}{l}P \\
\mathrm{mg} \mathrm{g}_{\text {soil }}^{-1}\end{array}$ & $\begin{array}{l}K \\
\mathrm{mg} \mathrm{g}^{-1} \\
\text { soil }\end{array}$ & $\begin{array}{l}\mathrm{Na} \\
\mathrm{mg} \mathrm{g}^{-1} \\
\text { soil }\end{array}$ & $\begin{array}{l}M g \\
\mathrm{mg} \mathrm{g}^{-1} \\
\text { soil }\end{array}$ & $\begin{array}{l}\mathrm{Ca} \\
\mathrm{mg} \mathrm{g}^{-1} \\
\text { soil }\end{array}$ & $\begin{array}{l}\mathrm{KAK}_{\text {pot }} \\
\mathrm{cmol} \mathrm{g}^{-1}\end{array}$ \\
\hline 0.0608 & 0.1150 & 0.0042 & 0.0166 & 0.5479 & 5.818 \\
\hline
\end{tabular}

sterilized with $3 \%$ bleach for 3 min and washed three times with water. The soil was fertilized in field with $\left(100 \mathrm{~kg} \mathrm{ha}^{-1} \mathrm{~N}, 22 \mathrm{~kg} \mathrm{ha}^{-1} \mathrm{~S}\right.$ and $\left.27 \mathrm{~kg} \mathrm{ha}^{-1} \mathrm{Mg}\right)$ and received a second fertilization $\left(\mathrm{N}, 44 \mathrm{mg} \mathrm{kg}^{-1}\right.$ soil) 30 days after emergence.

Four replicate samples of the initial planting soil were included in the analysis (Additional file 1: Table S1). During booting, flowering and milk ripening five replicate plants were sampled per crop species. Bulk soil was removed by slicing up the pot and tapping on the table. Thus, the soil aggregates were broken and loosely attached soil fell off when carefully shaking the root system. Two separate rhizosphere fractions were obtained: Distant rhizosphere (RZS) was collected by vigorous shaking and holding the plant at the stem, without hurting the root tissue. Close rhizosphere (RZP) refers to the soil layer remaining after mechanical collection of RZS. This fraction was recovered by placing the root system into $50 \mathrm{ml}$ tube with PBS buffer (pH 7.4), and putting on a rotary shaker (125 rpm, $5 \mathrm{~min}$ ). The detached soil suspension was than centrifuged at $4500 \times g$ for $10 \mathrm{~min}$ to sediment the rhizosphere. All samples for molecular analysis were frozen in liquid nitrogen and stored at $-80{ }^{\circ} \mathrm{C}$ until further processing.

\section{Soil chemical parameters}

The analysis of soil chemical parameters (Tables 1, 2) was performed at the facility 'Zentrallabor ZALF Müncheberg' following the methodology of respective DIN standard for ammonium, nitrate, soil $\mathrm{pH}$, total carbon $(\mathrm{Ct})$, total nitrogen $(\mathrm{Nt})$, total sulfur $(\mathrm{St})$, total inorganic carbon TIC and total organic carbon (TOC) or standard protocols recommended by the Association of German Agricultural Analytic and Research Institutes (VDLUFA) e.V.

\section{RNA extraction and purification}

RNA was extracted using a protocol adapted from two previously described protocols (Griffiths et al., 2000; Töwe et al., 2011). Briefly, $0.4 \mathrm{~g}$ rhizosphere sample were mixed in a bead tube (PowerBead Pro Tubes QIAGEN ${ }^{\circledR}$ ) with equal amounts of Hexadecyltrimethylammonium bromide (CTAB; $10 \%$ (wt/vol)) extraction buffer $(240 \mathrm{mM}$ potassium phosphate, $0.7 \mathrm{M} \mathrm{NaCl}, 10 \mu \mathrm{ml}^{-1} ß$-mercaptoethanol, $\mathrm{pH}$ 8) and phenol-isoamyl-chlorophorm with volumetric ratio of 25:24:1). Homogenization was performed twice for $40 \mathrm{~s}$ at a speed of $5.5 \mathrm{~m} \mathrm{~s}^{-1}$ in a bead mill (MP Biomedicals ${ }^{\mathrm{TM}}$ FastPrep-24 Instrument) interrupted by inverting the tubes for two minutes to avoid heat degradation. Followed by centrifugation for $(20 \mathrm{~min}$, $\left.4{ }^{\circ} \mathrm{C} 16,100 \times g\right)$. Resulting aqueous raw extract was recovered and purified twice with chloroform:isoamylalcohol (with volumetric ratio of 24:1). Subsequently, RNA was precipitated with $10 \%$ polyethyleneglycol 6000 while being incubated for $90 \mathrm{~min}$ on ice. The precipitate was recovered by centrifugation $\left(30 \mathrm{~min}, 4{ }^{\circ} \mathrm{C}, 16,100 \times g\right.$ ) and purified by washing with ice cold $70 \%$ ethanol. Subsequent to centrifugation $\left(5 \mathrm{~min}, 4^{\circ} \mathrm{C}, 16,100 \times g\right)$ the RNA pellet was suspended in $80 \mu \mathrm{l}$ RNAse-free water.

\section{RNA purification and CDNA synthesis}

The extract was digested with DNAse (TURBO DNAfree $^{\mathrm{TM}}$ Kit, Invitrogen ${ }^{\mathrm{TM}}$ ) to recover pure RNA extract. Obtained RNA concentration was measured at a fluorometer with a selective RNA binding dye (Qubit ${ }^{\mathrm{TM}}$ RNA BR Assay Kit). RNA quality was ensured with a value of two or higher in optical density ratio OD 260/280. Total RNA (200 ng) were than transcribed into cDNA (Biozym cDNA Synthesis Kit) within the same day. Pure RNA extracts were checked for residual bacterial DNA by $16 \mathrm{~S}$ rRNA PCR amplification (see 'PCR for amplicon sequencing preparation'). Absence of DNA, i.e. lack of an amplicon, was proven by subsequent gel electrophoresis and only such checked RNA solutions were used for further steps.

\section{PCR for amplicon sequencing preparation}

Bacterial composition was analyzed by amplicon sequencing of the reverse transcribed $16 \mathrm{~S}$ rRNA as phylogenetic marker. The hypervariable V4 region was targeted using the primers 515F-806R [36, 37] with terminal universal adapter sequences to link DNA barcodes and 
sequencing adaptors. $50 \mu$ l PCR consisted of GoTaq $^{\circledR}$ G2 Hot Start Master Mix, primer $(0.1 \mu \mathrm{M})$ and $4 \mu \mathrm{l}$ cDNA template (1:50 dilution). The thermal program was $95^{\circ} \mathrm{C}$ for $120 \mathrm{~s}, 25$ cycles of $95{ }^{\circ} \mathrm{C}$ for $40 \mathrm{~s}, 56^{\circ} \mathrm{C}$ for $30 \mathrm{~s}, 72^{\circ} \mathrm{C}$ for $40 \mathrm{~s}$ and a final elongation at $72{ }^{\circ} \mathrm{C}$ for $300 \mathrm{~s}$. Amplicon size homogeneity was verified by gel electrophoresis. A pooled negative control of all PCR runs was included. Further library preparation and $300 \mathrm{bp}$ paired-end read Illumina Miseq V3 sequencing were performed by LGC genomics GmbH Berlin.

\section{Bioinformatic pipeline for analysis of amplicon sequencing dataset}

Demultiplexing was conducted with Illumina bcl2fastq 2.17.1.14 software following clipping of barcode and sequencing adapters. Primer were removed using Cutadapt v3.0 (Martin, 2011) following sequence processing using QIIME 2 v2020.8 [38]. Denoising was performed by applying the build in method for DADA2 [39] with forward and reversed reads truncated at $250 \mathrm{bp}$ and $200 \mathrm{bp}$, respectively. Amplicon sequencing variants (ASV) were assigned to taxonomy using the naïve bayesian classifier for Silva 138. 99\%-OTUs from 515F/806R region of sequences [40, 41]. A phylogenetic tree was generated using IQ-TREE 2 [42]. The pipeline started from $14,819,213$ singles reads and yielded 10,810,699 non chimeric sequences, which corresponds to an average recovery of 85,799 sequences or $70 \%$ per sample $(n=125)$. Subsequent to removal of unidentified taxa beyond species level and plastid sequences, 11,710 non-singleton AVSs were obtained, of which 6817 occurred in more than one sample. These belonged to 36 bacterial phyla and 590 genera.

\section{Statistical and network analysis}

Statistical analysis was conducted in R v3.6.0-4.0.0 [43] and Rstudio [44]. Filtering and storage of sequencing data were carried out using phyloseq [45] and visualization were produced by ggplot2 [46] and circilize [47]. Alpha diversity was calculated using the inverse Simpson index, observed ASVs and Shannon index based on rarefactioned counts to $10^{4}$ reads per sample (Additional file 1: Figure S1). Multivariate statistics namely Principal coordinates analysis $(P C O A)$ and Permutational analysis of variance (PERMAOVA) to test the effect of crop species, plant growth stage, and rhizosphere compartment on overall variance of the bacterial microbiota composition were conducted using the ordinate and adonis2 function of the vegan package [48]. PCoA analysis was computed based on weighted UniFrac distance. Core bacterial microbiota of the close and distant rhizosphere for each of the four crop species were computed and defined as
ASVs occurring at all three growth stages and in all four replicates $(\mathrm{n}=3 \times 5)$.

Linear discriminant analysis effect size (LEfSe) [31] was applied to identify biomarker taxa explaining differences between core bacterial microbiota of the crop species and both rhizosphere compartments (RZP, RZS). Co-occurrence networks of the eight core bacterial microbiota were computed with the SPRING model [49]. Network analysis was performed with the NetCoMi package [50]. Hubs were identified as nodes above the $95 \%$ quantile of the fitted log-normal distribution of the three normalized network metrics degree, betweenness and closeness centrality. Hubs were further investigated regarding their direct associations referred to as cohort nodes. Network comparison required to subset to ASVs present in both core bacterial microbiota under investigation. Differential associations were verified using the discordant method [51].

\section{Results}

\section{Niche partioning and partially host and growth stage explain rhizosphere bacterial microbiota variation}

The variation in the bacterial microbiota considering all plant hosts and growth stages was mainly affected by spatial differentiation in the rhizosphere as indicated by $21 \%$ of variance explained $\left(R^{2}\right)$ by contrasting close and distant rhizosphere (PERMANOVA). Additionally, both rhizosphere compartments were significantly different from the initial bulk soil (Table 3). Crop species and growth stage accounted for $10 \%$ and $6 \%$ respectively, with all factors being statistically significant $(P<0.001)$ (Table 4).

Looking at the individual compartment, we observed a stronger growth stage effect in the distant $\left(R^{2}=34 \%\right)$ than in close rhizosphere $\left(R^{2}=11 \%\right)$. Crop species captured a significant proportion of microbiome variation, which was around $18 \%$ and $12 \%$ in the distant and close

Table 3 Divergence of rhizosphere from initial planting soil bacterial microbiota composition

\begin{tabular}{llllll}
\hline Factor & Df & SumOfSqs & $\boldsymbol{R}^{\mathbf{2}}$ & $\boldsymbol{F}$ & $\boldsymbol{P}^{*}$ \\
\hline Rhizosphere vs bulk soil & 2 & 0.645 & 0.304 & $23.611<.001$ \\
Residual & 108 & 1.476 & 0.706 & & \\
Close rhizosphere vs. bulk & 55 & 0.172 & 10.204 & $114.11<.001$ \\
soil & & & & & \\
Residual & 56 & 0.669 & 0.796 & & \\
$\begin{array}{l}\text { Distant rhizosphere vs. bulk } \\
\text { soil }\end{array}$ & 56 & 0.268 & 0.245 & $18.157<.001$ \\
Residual & 57 & 0.826 & 0.755 & & \\
\hline
\end{tabular}

Permutational analysis of variance and weighted UniFrac distance

* Bold font: factors considered significant 
Table 4 Influence of rhizosphere compartment, crop species, and growth stage on entire and core bacterial microbiota

\begin{tabular}{|c|c|c|c|c|c|}
\hline Factor & Df & SumOfSqs & $R^{2}$ & $F$ & $P^{*}$ \\
\hline \multicolumn{6}{|c|}{ Full dataset (close \& distinct rhizosphere) } \\
\hline Growth stage & 2 & 0.108 & 0.057 & 4.969 & $<.001$ \\
\hline Crop species & 3 & 0.188 & 0.100 & 5.838 & $<.001$ \\
\hline $\begin{array}{l}\text { Rhizosphere } \\
\text { (close\&distant) }\end{array}$ & 1 & 0.425 & 0.225 & 39.53 & $<.001$ \\
\hline $\begin{array}{l}\text { Growth stage:crop spe- } \\
\text { cies }\end{array}$ & 6 & 0.156 & 0.083 & 2.421 & $<.001$ \\
\hline Residual & 94 & 1.01 & 0.535 & & \\
\hline \multicolumn{6}{|c|}{ Core bacterial microbiota distant rhizosphere } \\
\hline Growth stage & 2 & 0.081 & 0.020 & 8.398 & $<.001$ \\
\hline Crop species & 3 & 3.694 & 0.918 & 253.680 & $<.001$ \\
\hline $\begin{array}{l}\text { Growth stage:crop spe- } \\
\text { cies }\end{array}$ & 6 & 0.031 & 0.008 & 1.076 & 0.394 \\
\hline Residual & 0.218 & 0.054 & & & \\
\hline \multicolumn{6}{|c|}{ Core bacterial microbiota close rhizosphere } \\
\hline Growth stage & 2 & 0.119 & 0.030 & 8.842 & $<.001$ \\
\hline Crop species & 3 & 3.384 & 0.851 & 166.968 & $<.001$ \\
\hline $\begin{array}{l}\text { Growth stage:crop spe- } \\
\text { cies }\end{array}$ & 6 & 0.195 & 0.049 & 4.807 & $<.001$ \\
\hline Residual & 41 & 0.277 & 0.070 & & \\
\hline \multicolumn{6}{|c|}{ Bacterial microbiota distant rhizosphere } \\
\hline Growth stage & 3 & 0.380 & 0.347 & 14.685 & $<.001$ \\
\hline Crop species & 3 & 0.199 & 0.182 & 7.698 & $<.001$ \\
\hline $\begin{array}{l}\text { Growth stage:crop spe- } \\
\text { cies }\end{array}$ & 6 & 0.127 & 0.116 & 2.454 & $<.002$ \\
\hline Residual & 45 & 0.388 & 0.355 & & \\
\hline \multicolumn{6}{|c|}{ Bacterial microbiota close rhizosphere } \\
\hline Growth stage & 2 & 0.075 & 0.115 & 4.209 & $<.001$ \\
\hline Crop species & 3 & 0.084 & 0.129 & 3.150 & $<.001$ \\
\hline $\begin{array}{l}\text { Growth stage:crop spe- } \\
\text { cies }\end{array}$ & 6 & 0.126 & 0.195 & 2.370 & $<.001$ \\
\hline Residual & 41 & 0.365 & & & \\
\hline
\end{tabular}

Based on permutational analysis of variance and weighted UniFrac distance Core bacterial microbiota of wheat, barley, rye and oilseed rape includes ASVs present within each replicate per crop species and at every growth stage (booting, flowering, ripening)

* Bold font: factors considered significant

rhizosphere, respectively. We found a significant interaction between plant growth stage and crop species, which explained an additional $12 \%$ of variation in both rhizosphere compartments. This suggests a differential response of the bacterial microbiota associated with a specific plant growth stage in different crop host species. PCoA on weighted UniFrac distance resembled the separation of the close from the distant rhizosphere as primary effect (Fig. 1A, B). Bacterial microbiota assembly of cereal species and oilseed rape diverged at booting, but tended to converge at mid and late growth stages. Contrastingly, barley and oilseed rape were temporally invariant within the distant rhizosphere and formed separate clusters. Rye and wheat associated with barley at booting and diverged between flowering and late growth stages. Hence, the distance to oilseed rape decreased implying a temporal shift in microbiome structure.

\section{The core rhizosphere bacterial microbiota encompassed growth stage-invariant Bacteria enriched within individual crop species}

Host-species effect signatures within the rhizosphere bacterial microbiota were inferred from eight core bacterial microbiota for each host species separated into close and distant rhizosphere (Additional file 1). The core bacterial microbiota gathered from joint datasets of all four crop species represented more than half of summed ASV counts (RZP 58\%, RZS 50\%), but were limited to a low fraction of ASVs (8\%) (Table 5).

This implies, that a low number of core Bacteria were the dominant microbiota associated with the four crops studied. Moreover, PCoA analysis demonstrated an uniform clustering by crop species within the core bacterial microbiota independent of growth stage (Fig. 1C, D), with the host plant effect explaining almost the entire variation (PERMANOVA, $\mathrm{R}^{2}=92 \mathrm{RZS}, \mathrm{R}^{2}=82 \mathrm{RZP}$ ). Thus, the core bacterial microbiota derived in our study encompassed plant host-specific Bacteria. These originate from a typical arable soil and can be considered as non-transient host traits, since they persisted over growth stages.

For taxonomic description, the core bacterial microbiota were aggregated at the genus level. Generally, more than two genera unique to each crop species (ratio RZS:RZP) occurred in wheat (15:26) and barley (12:5), i.e. with a total abundance below $1.5 \%$ of total sequences count within the core microbiota (Fig. 2). Thus, unique genera were scarce and might belong to the rare species pool. Contrastingly, the 52 (distant rhizosphere) and 44 (close rhizosphere) genera that occurred in all four crop core bacterial microbiota of the respective rhizosphere compartment were highly abundant (about $80 \%$ of total sequences count), meaning that this comparable small subset were dominant traits of the core microbiota. Additionally, more than ten genera were shared between the three cereals or between barley, wheat an oilseed rape thereby contributing to more than $5 \%$ of the total sequences counts within the aggregated core microbiota. As a consequence, enriched or depleted genera were the most abundant core microbiota members for each of the four crop species, while unique bacterial genera were scarce.

The aggregated core microbiota were predominantly composed of the genera of the classes Alpha- and Gammaproteobacteria, Actinobacteria, Thermoleophilia, 

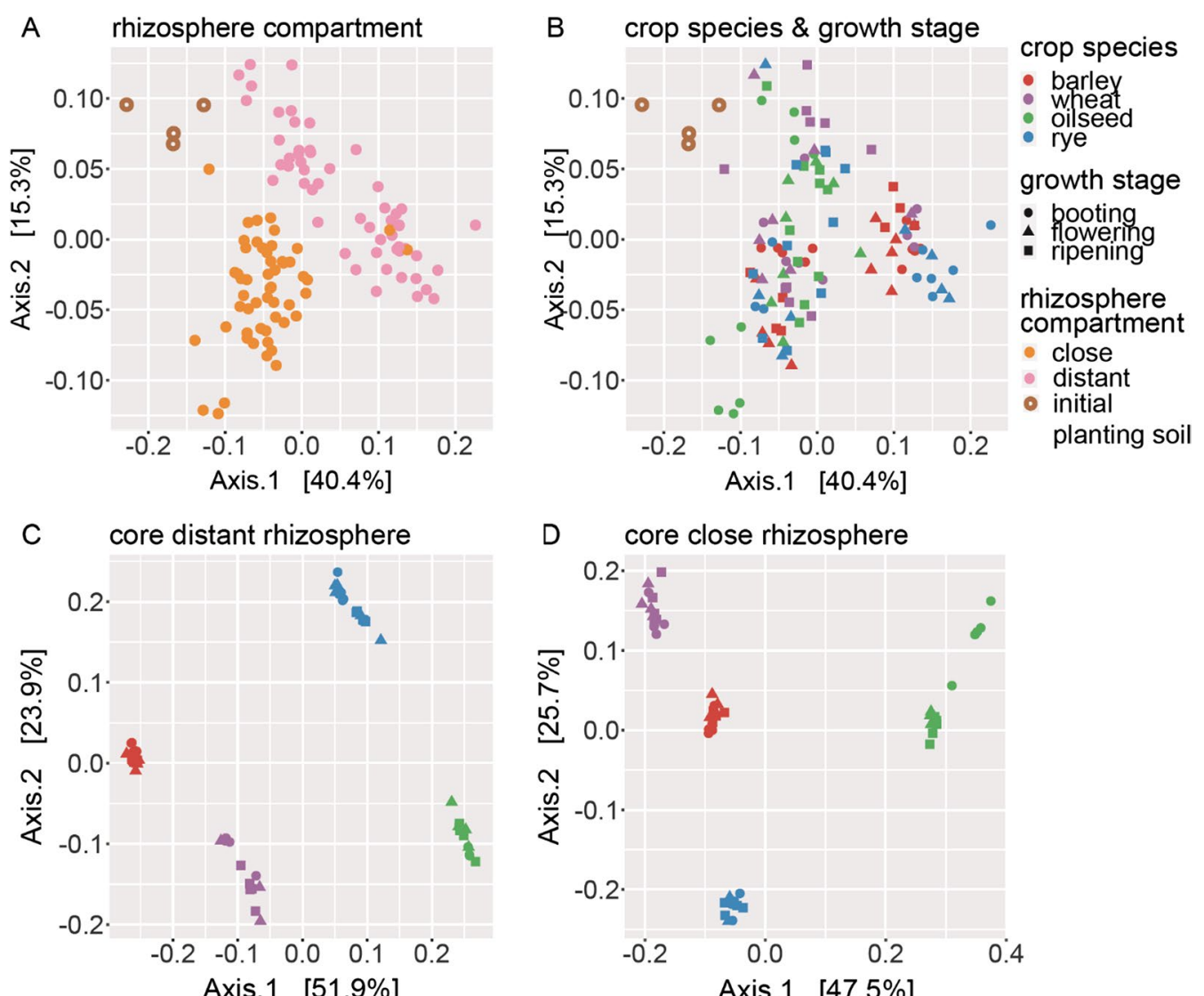

Fig. 1 Principal Coordinates Analysis using weighted UniFrac distance for unfiltered bacterial microbiota A by rhizosphere compartment, B by crops species and growths stages and for the core rhizosphere microbiota of wheat, barley, rye and oilseed rape for the $\mathbf{C}$ distant and $\mathbf{D}$ close rhizosphere

Table 5 Number and relative abundance of ASVs included in the host crop core microbiota

\begin{tabular}{|c|c|c|c|c|c|}
\hline Rhizosphere compartment & Wheat & Barley & Rye & Oilseed rape & Agglomerated \\
\hline \multicolumn{6}{|l|}{ Distant } \\
\hline ASVs & 283 & 345 & 154 & 122 & 453 \\
\hline ASVs (\% of total)* & 4.6 & 5.6 & 2.5 & 2 & 8.1 \\
\hline ASV count ( $\%$ of total)* & 11.6 & 12.8 & 8.3 & 8.4 & 50.2 \\
\hline \multicolumn{6}{|l|}{ Close } \\
\hline ASVs & 446 & 296 & 203 & 137 & 512 \\
\hline ASVs (\% of total) & 7.0 & 4.8 & 3.3 & 2.2 & 8.3 \\
\hline Sequence count (\% of total) & 21.0 & 13.0 & 9.2 & 15.0 & 58.0 \\
\hline
\end{tabular}

* Proportion of ASVs and ASV counts in relation to the unfiltered microbiota

Bacilli, Verrucomicrobia, unclassified Chloroflexi of the group KD4-96', which together accounted for more than $50 \%$ of relative abundance. Proteobacteria were more abundant within the close rhizosphere, whereas genera of the Thermoleophilia and 'TK10' were lower abundant than in distant rhizosphere. Genera of the class Bacilli were substantially enriched (25\%) in oilseed rape close rhizosphere. Exclusive bacterial genera of barley belonged mainly to the Alpha- and Gammaproteobacteria (close rhizosphere) or Actinobacteria, Acidobacteria, Planctomycetes (distant rhizosphere). In contrast to barley, genera of the Bacilli and Polyangia were uniquely present in the distant rhizosphere of wheat.

Genera exclusively shared between barley, wheat, and oilseed rape belonged mainly to the Alpha- and Gammaproteobacteria and were characterized by the 


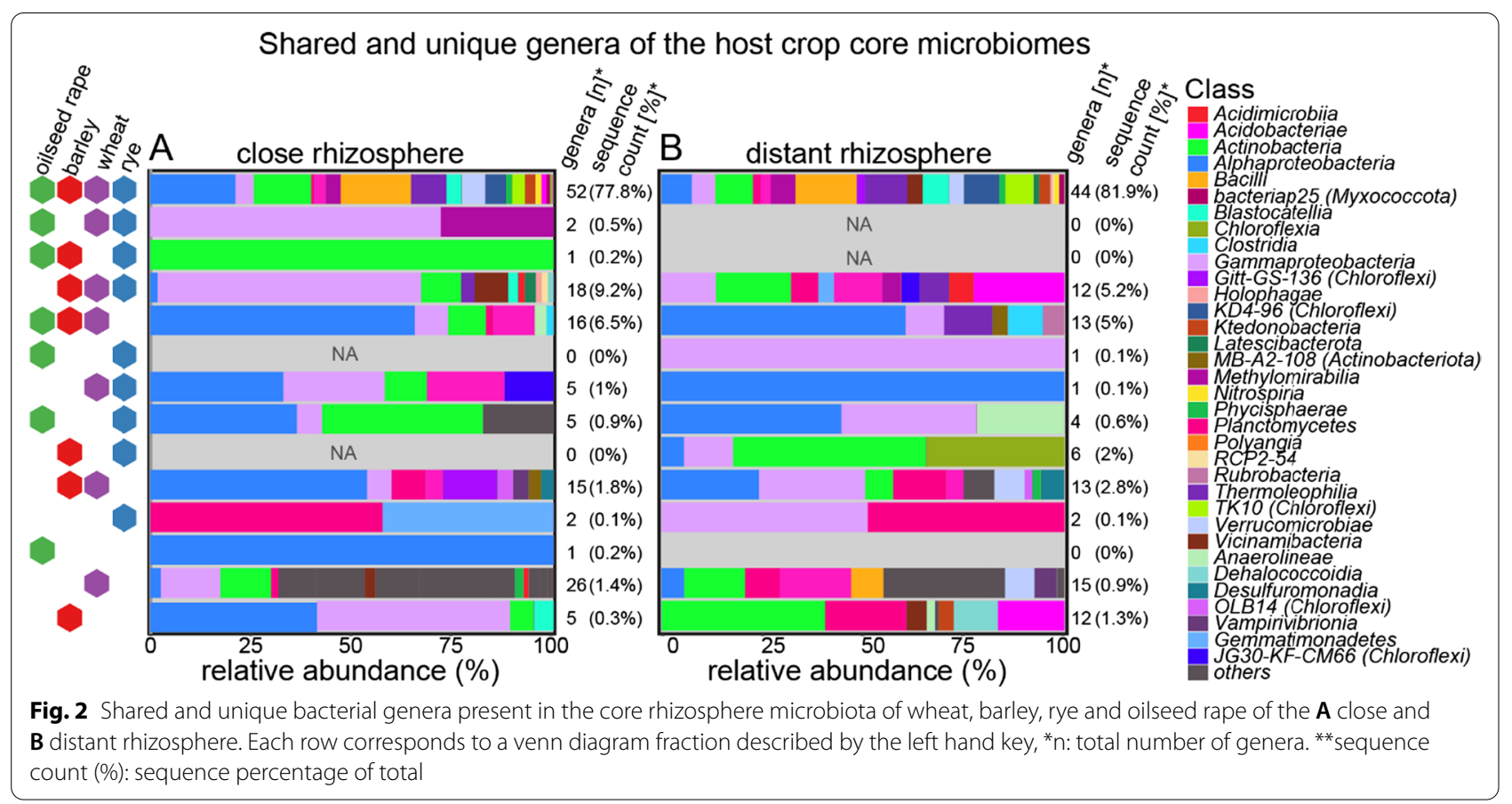

presence of Rubrobacteria and Clostridia. Remarkably, genera exclusively found in cereals were mainly Gammaproteobacteria but no Alphaproteobacteria.

The primary result of both core inference and venn diagram partitions was that shared genera between all crop species and triplicate comparison incorporate most of the of the total sequences counts of the aggregated core microbiota. In contrast, unique genera of the crop species microbiota exhibited low aggregated sequence counts.

\section{LEfSe biomarker analysis}

Most genera were present across core bacterial microbiota of all crop species. Hence, we identified biomarker taxa from genus to phylum rank among them using LEfSe analysis. These biomarker were the dominant bacterial phylotypes associated with a specific crop species and were the main taxa that explained differences between the core bacterial microbiota of the four crops species (Fig. 3 and Table 6).

Additionally, we determined bacterial genera characteristic of spatial differentiation between the close and distant rhizosphere based on the entire dataset irrespective of the crop species (Additional file 1: Figure S2).
One third of the biomarker taxa occurred in both rhizosphere compartments but were indicative of two different crop species (Fig. 3C1). Among them several lower taxonomic groups of the Gammaproteobacteria were indicative of oilseed rape within the distant rhizosphere, whereas these were a biomarker taxon of rye or barley in the close rhizosphere. The families Blastocatellia and Dokdonella were biomarker taxa of rye in the close rhizosphere and belonged to oilseed rape in the distant rhizosphere. Accordingly, several biomarker that were assigned to oilseed rape in the distant rhizosphere, were assigned to wheat within the close rhizosphere, e.g. Paenbacillus or Bradyrhizobium Additionally, several biomarker taxa of a crop species bacterial microbiome identified in the close rhizosphere became non-discriminative in the distant rhizosphere. This was most apparent for biomarker taxa belonging to the order Rhizobiales. Interestingly, Bacillus and Streptomyces were biomarker of oilseed rape in both compartments. Further, the bacterial microbiota of barley tended to show identical biomarkers in both rhizosphere compartments, such as the family Gemmataceae or the genus Candidatus Alysiosphaera.

(See figure on next page.)

Fig. 3 Biomarker taxa of wheat, barley, rye and oilseed rape bacterial core microbiota at the genus rank derived from the close and distant rhizosphere identified by linear discriminant analysis effect size (LEfSe**) visualized as circular taxonomic trees. A distant rhizosphere; $\mathbf{B}$ close rhizosphere; $\mathbf{C} 1$ Biomarker from order to genus rank occurring in both rhizosphere compartments; $\mathbf{C 2}$ Biomarker from order to genus exclusive to the close rhizosphere; $\mathbf{C 3}$ Biomarker from order to genus exclusive to the distant rhizosphere ** LEfSe: Linear discriminant analysis effect size 


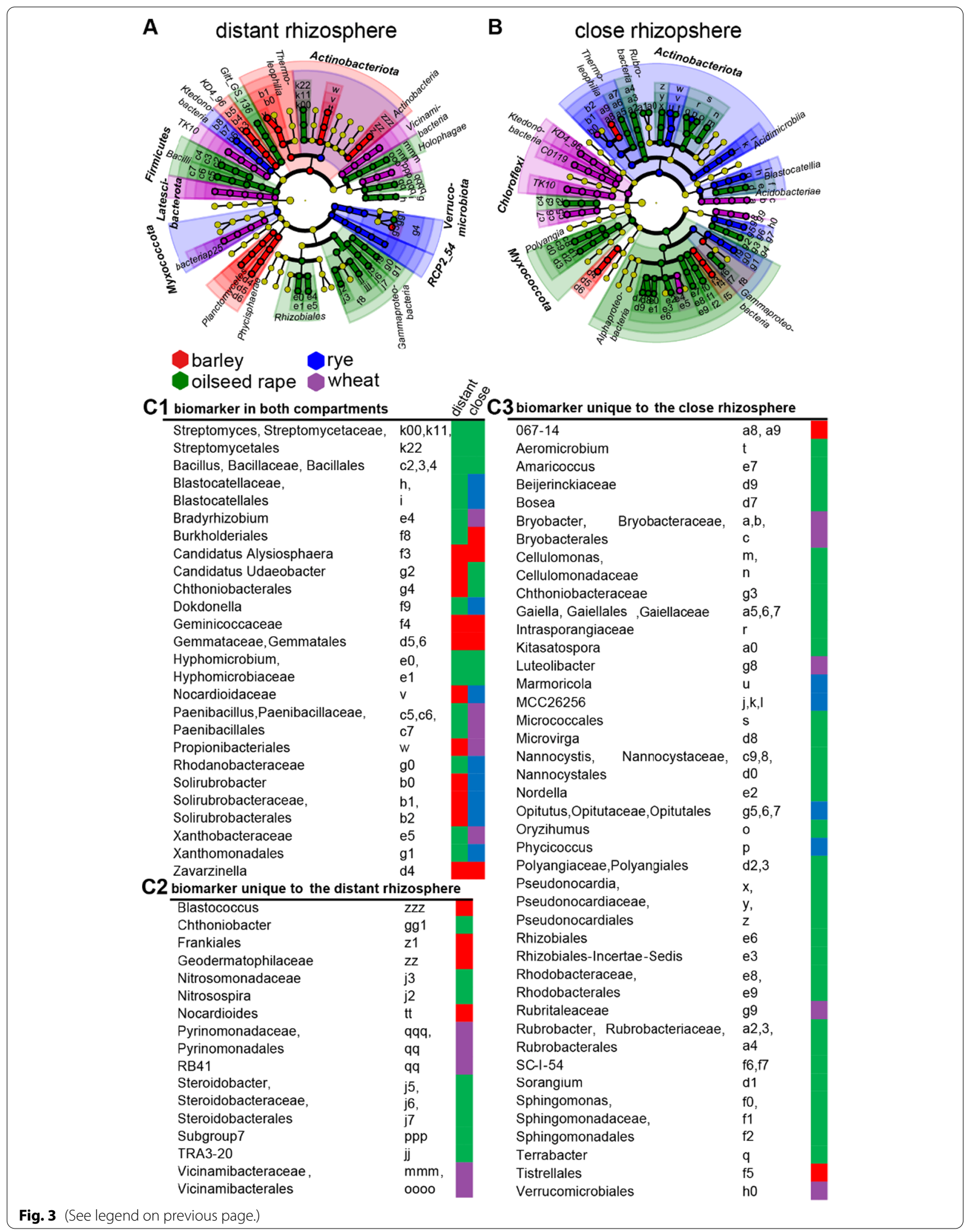


Table 6 Global co-occurrence network metrics for each core microbiota of the crop species and rhizosphere compartment

\begin{tabular}{lllllllll}
\hline Niche & Crop species & Nodes & $\begin{array}{l}\text { Clustering } \\
\text { coefficient }\end{array}$ & Modularity & $\begin{array}{l}\text { Positive } \\
\text { edges (\%) }\end{array}$ & Average degree & $\begin{array}{l}\text { Average } \\
\text { betweenness }\end{array}$ & $\begin{array}{l}\text { Natural } \\
\text { connectivity }\end{array}$ \\
\hline Close & Barley & 107 & 0.083 & 0.563 & 50 & 0.035 & 0.028 & 0.011 \\
& Wheat & 139 & 0.098 & 0.483 & 56 & 0.036 & 0.017 & 0.009 \\
& Rye & 77 & 0.119 & 0.608 & 52 & 0.036 & 0.048 & 0.015 \\
& Oilseed rape & 71 & 0.156 & 0.604 & 51 & 0.041 & 0.043 & 0.016 \\
\multirow{5}{*}{ Distant } & Barley & 99 & 0.091 & 0.512 & 52 & 0.040 & 0.027 & 0.012 \\
& Wheat & 102 & 0.087 & 0.530 & 55 & 0.039 & 0.012 & 0.054 \\
& Rye & 61 & 0.133 & 0.645 & 51 & 0.040 & 0.078 & 0.019 \\
& Oilseed rape & 58 & 0.089 & 0.677 & 47 & 0.038 & & 0.078 \\
\end{tabular}

Biomarker of rye belonged uniformly to the close rhizosphere, e.g. Optitutaceae. The majority of biomarker taxa exclusively derived from the close rhizosphere belonged to the bacterial microbiota of oilseed rape such as Sphingomonas and Pseudnarcodia (Fig. 3B, C3). Verrucomicrobiales were a unique biomarker of wheat within the close rhizosphere. Biomarker exclusively detected in the distant rhizosphere that belonged to barley were among other the order Frankiales and Nocardioides.

Thus, the rhizosphere compartment essentially determined biomarker taxa assignment. Thereby, we observed assignments of the same biomarker taxa to different crop species only differing by the two rhizosphere compartments. This required further investigations of the identified individual biomarker genera and the underlying differences between hosts core microbiota, they were characteristic of. Thus, we examined co-occurrence patterns of the core bacterial microbiota to confirm host specificity and the structural importance of so far identified biomarker genera.

\section{Network hubs of the crop core bacterial microbiota}

We performed co-occurrence network analyses for each core bacterial microbiota visualized as chord diagrams to identify structurally important interactions within the individual crop bacterial microbiota in separated data sets of the close and the distant rhizosphere (Additional file 1: Figures S3, S4).

The size of the largest connected component was 1.5fold larger in wheat and barley, compared to rye and oilseed rape (Table 5). Higher average degree, betweenness and natural connectivity were observed in all networks of the close compared to the distant rhizosphere. Similarly higher average degree, betweenness and natural connectivity were observed for the networks of rye and oilseed rape compared to barley and wheat (Table 5). Accordingly, the network structure of wheat and barley was more dependent on individual nodes compared to the other host plant species.
More than ten hubs were identified for wheat and barley within the close rhizosphere, which interconnected almost the entire network (Fig. 4, 5), while rye and oilseed rape comprised less than four hubs that were directly associated with less than 16 cohort nodes (Figs. 4, 5). The networks of wheat, rye and oilseed rape within the distant rhizosphere comprised less than three hubs, which directly connected only a small subset of cohort nodes. In contrast, the seven hubs of barley form a complex subnetwork with their cohort nodes similarly to the close rhizosphere. As a result, the co-occurrence networks of (a) rye and oilseed rape as well as of (b) wheat and barley are structurally more similar to each other, respectively.

Hubs shared between at least two cereal crop species in the close rhizosphere were Massilia, Rubrobacter, and Phycicococcus. Thereby, more than three hubs of barley and wheat belonged to the class Alphaproteobacteria. Hubs of wheat, barley and to a lower extent of rye associated with similar nodes. Individual hubs of oilseed rape were unclassified Chloroflexi group 'KD4-96', Phenylobacterium, and Rubrobacter. Exclusive hubs of wheat were among others Steroidobacter, Glycomyces, Vampirovibrionales, Clostridium ss.13 and Solirubrobacter. The only hubs exclusively found in rye were Kitasatospora and unclassified Pyrinomonadaceae 'RB41'. Remarkably, Nitrospira was an exclusive hub of barley, which was not associated with cohort nodes in the other crop species (Fig. 4).

\section{Differentially associated nodes of the bacterial rhizosphere core microbiota}

We examined pairwise significant differences in associations of shared genera between each crop core bacterial microbiota to demonstrate that the core taxa across crop species distinctively influence the bacterial microbiota structure and assembly. In most comparisons (Figs. 6, 7), half of the differentially associated nodes belonged to the Alphaproteobacteria and Actinobacteria. The most frequent and differentially associated genera (Table 7) 


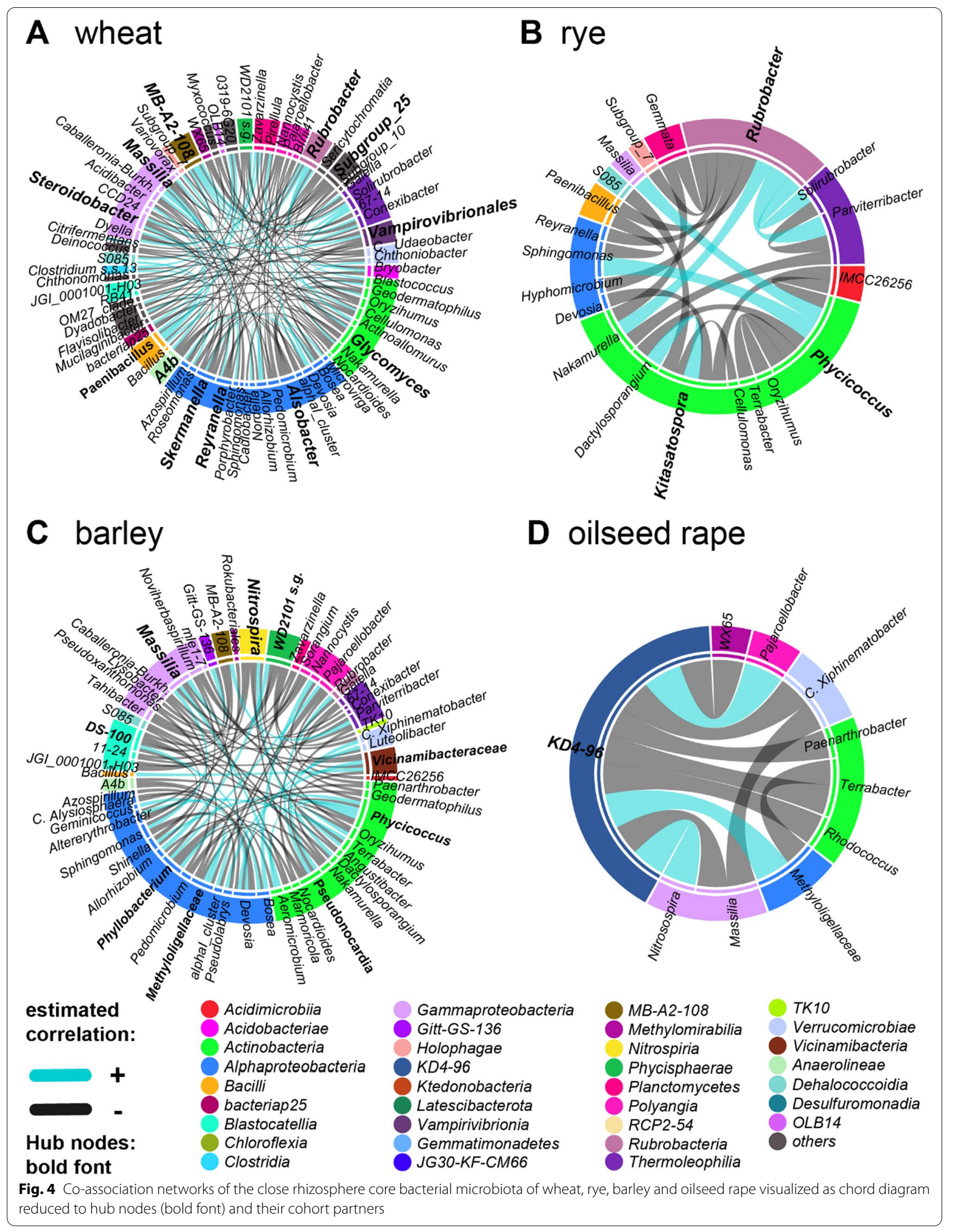




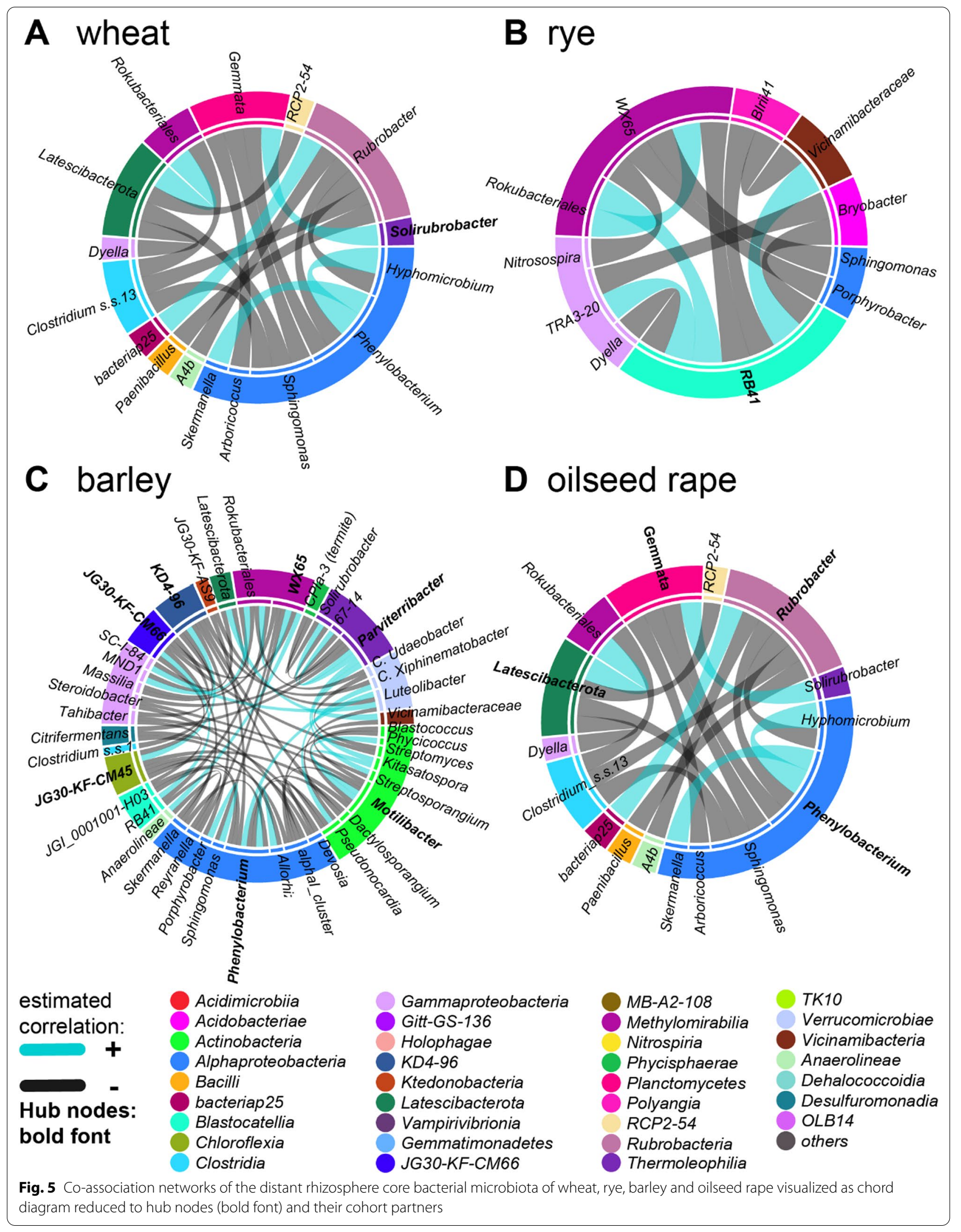




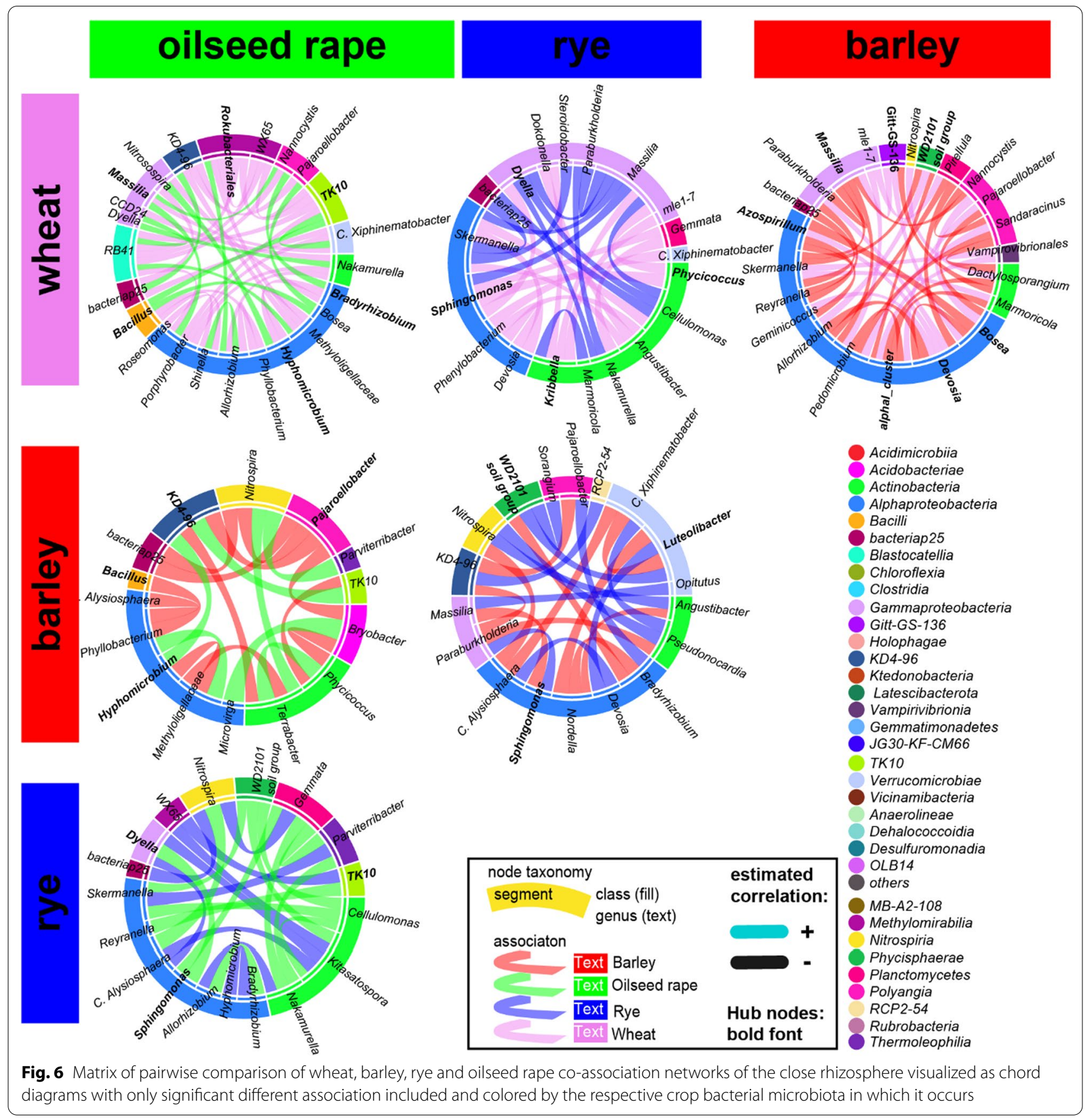

were unclassified Tepidisphaeraceae 'WD2101 soil group', Hyphomicrobium, Terrabacter, uncultured Beijerinckiaceae 'alphaI cluster', Nocardioides, Massilia, and Bradyrhizobium.

While Bradyrhizobium was identified as a hub of oilseed rape, the association of Bradyrhizobium and Hyphomicrobium was specific to the three cereals. Another specific feature of cereals was the association of Nocardioides and uncultured Beijerinckiaceae 'alphaI cluster' (only wheat and barley) with unclassified Tepidisphaeraceae of the group 'WD2101 soil group', while in oilseed rape Nocardioides formed associations with other genera of the Actinobacteria, such as Streptomyces. Differential associations contrasting the individual cereal crop species were formed by Cellulomonas and Skermanella as well as unclassified Pyrinomonadaceae 'RB41' for rye. Significant different association specific to wheat and barley were guided by Massilia, Sphingomonas, Bosea, 


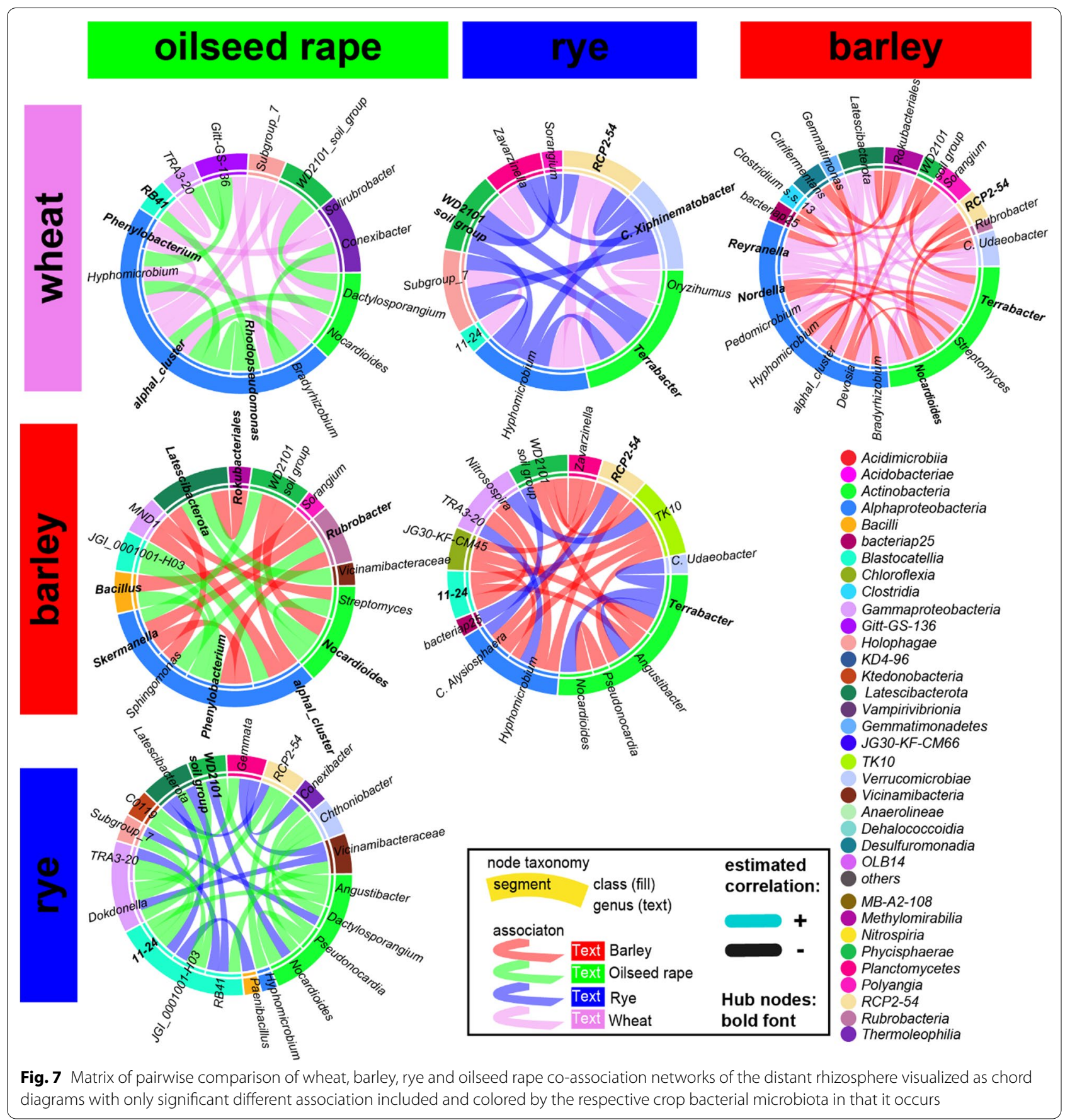

Devosia and Candidatus Xiphinematobacter as well as Optitutus in rye. Thus, a limited set of genera promoted different microbiome structures between the crop species. These shared genera were indicative of differences between cereal crops and oilseed rape and between individual crop species. Moreover, cereal hosts tended to associate with similar nodes compared to oilseed rape.
As a result, co-occurrence network analyses explained differences in rhizosphere microbiome assembly between plant families as well as individual crop species. Thus, cohort subnetworks and differential associations elucidated a host species effect that was not evident from differential abundance of specific bacterial genera enriched or unique to a specific plant host. 
Table 7 Most frequent* significant differential associated nodes within pairwise comparisons of the crop species ${ }^{* *}$ core bacterial microbiota co-association networks

\begin{tabular}{lll}
\hline Rhizosphere & \multicolumn{2}{l}{$\begin{array}{l}\text { Number of differential } \\
\text { associations }\end{array}$} \\
\cline { 2 - 3 } & Close & Distant \\
\hline WD2101_soil_group & 32 & 26 \\
Hyphomicrobium & 31 & 23 \\
Terrabacter & 28 & 21 \\
alphal_cluster & 27 & 19 \\
Skermanella & $\mathrm{NA}$ & 17 \\
Nocardioides & 25 & $\mathrm{NA}$ \\
Nitrospira & 21 & $\mathrm{NA}$ \\
Massilia & 21 & 17 \\
TK10 & $\mathrm{NA}$ & 15 \\
Bradyrhizobium & 21 & 14 \\
Devosia & $\mathrm{NA}$ & 14 \\
\hline
\end{tabular}

*0.9 percentile

** Barley, wheat, rye and oilseed rape

\section{Discussion}

A glasshouse experiment was conducted to investigate if host species-specific keystone Bacteria persist within the metabolically active rhizosphere bacterial microbiota of typical crop plant hosts. We demonstrated a general plant rhizosphere effect. Subsequently, crop-specific core microbiota were derived to delineate their keystone $\mathrm{Bac}$ teria based on co-occurence networks. Differential associations of the core microbiota of each crop species were resolved that comprehensively characterize host signatures within the rhizosphere microbiota.

\section{Plant host filtering had a subsidiary effect}

A robust rhizosphere effect [15] was observed for all four crop species resulting in rhizosphere bacterial microbiota distinct from the initial soil microbiota composition and profound contrasts between the close and distant rhizosphere compartment were confirmed. This implies that root traits and activity had a different spatial impact on the bacterial microbiota structure, irrespective of plant species. However, the distant rhizosphere bacterial microbiota of oilseed rape remained more similar to the bacterial microbiota of the initial bulk soil. In contrast, the bacterial microbiota of oilseed rape within the close rhizosphere exhibited the most pronounced crop species effect. This suggests that the rhizosphere effect reached shorter than compared to the monocot cereal species. Poaceaes and Brassicaceae differ in root anatomy and growth regulation $[52,53]$. Moreover, the production of glucosinolates typical to Brassica $[54,55]$ might have inhibited some microbiota that were not affected by cereal crop species' roots. A mechanistic analysis is not the scope of the current study. However, the rhizosphere compartment ultimately determined rhizosphere microbiota composition, which is essential to future RNA- and transcriptome-based study designs.

Crop species and developmental impact on the bacterial microbiota were tightly coupled within the close rhizosphere as implied by a significant effect in interaction of crop species and growth stage in PERMANOVA analysis. The explained variance was larger than previously reported when comparing plant genotypes [15], but the crop species effect alone had only a low impact compared with previous field studies that involved cereal crop species [30]. Our study accessed only the metabolic active part of the bacterial microbiota that may per se respond more pronouncedly to host temporal variability in root metabolism. Rhizosphere-competent microbiota are generally characterized by both fast growth and rapid upregulation of gene expression [56]. Thus, they can better adapt to conserved metabolic dynamics of the plant during growth [57]. Consequently, the rhizosphere bacterial microbiota assembly was clearly linked to plant host species traits. In agreement with previous studies, the plant host effect was spatiotemporally dynamic and subsidiary to the general rhizosphere effect.

\section{Host species-specific genera occur in the core rhizosphere bacterial microbiota}

Accounting for the assembly effect of soil and host factors in the rhizosphere [58], we derived core bacterial microbiota of oilseed rape, barley, rye and wheat, respectively. In turn, microbiome assembly patterns were affected only by host plant species-specific acquirement, since the variation of the merged core bacterial microbiota was almost entirely explained by the factor crop species. Prevalent bacterial taxa belonged to the shared fractions. This suggests a refinement from an established rhizosphere instead of parallel acquirement from bulk soil, which would have led to host plant-unique identities of bacterial taxa. Hence, the two-step selection model [10] applies to our results that postulates a host fine-tuning of the rhizosphere bacterial microbiota.

Generally, in our study we observed an increased importance of Gammaproteobacteria in the bacterial microbiota of cereals. The taxonomic composition of the core bacterial microbiota broadly covers Bacteria found in previous studies. These examined the plant host effect on rhizosphere microbiome of wheat, oilseed rape, and further cereals with reduced environmental settings [16, $21,52,59,60]$, or as field studies [27, 34].

We identified LEfSe biomarkers explaining differences between the four core bacterial microbiota of 
crop species. Paenibacillus, Verrucomicrobiales, and Bradyrhizobium [59] or Rhodanobacteriacea [27] were associated with wheat and oilseed rape in contrast to findings of previous studies. [27, 59]. Further, Bacillus was characteristic to both rhizosphere compartments of oilseed rape in our study, whereas a previous study reported that it was specific for wheat and barley [30]. Bacillus species offer a multitude of plant-beneficial traits [61], which might be differentially selected for by either wheat or oilseed rape. Some host-specific bacterial microbiota patterns only prevail within a specific environmental context, such as edaphic conditions [13, 60], crop rotation [27], and nitrogen fertilization regime [62], while others are considered heritable [57]. Additionally, in our study we observed assignments of the same biomarker taxa to different crop species only differing by the two rhizosphere compartments We found an assignment of Streptomycetaceae as a biomarker of oilseed rape rhizosphere microbiome. On the other hand, they are observed to be recruited to the wheat root endosphere, but are consuming root exudate within the rhizospheres [60]. Hence, their plant host-specific recruitment might be restricted to the endosphere compartment, while they only traverse the rhizosphere microbiome. In conclusion, the enrichment of individual biomarker taxa to a specific plant-host was not apparent from the LEfSe biomarker analysis. Based on unexpected and contrasting findings of $L E f S e$ biomarker assignment to a crop species between the close and distant rhizosphere and compared to previous studies, we argue that additional techniques such as network analyses are necessary to delineate nontransient host-specific signatures within the rhizosphere microbiome and to rule out artefacts.

\section{Keystone Bacteria of the rhizosphere core microbiota are differentially associated among crops species}

A functional perspective on the bacterial microbiota assembly [63] in regard to plant-beneficial effects seems to be a promising route to elucidate rhizosphere bacterial microbiota assembly, which can be considered as a result of functional rather than purely phylogenetic selection [5, 63]. We hypothesized that the host signatures discriminating host-specific bacterial microbiota persisting in our study rely on hub and differential associations of Bacteria as inferred from co-occurrence networks analyses. Since the bacterial microbiota description was based on active Bacteria, the observed associations likely reflected functionally relevant patterns of bacterial microbiota interconnection and indirect trophic links with the plant host [32].

Differences between the structures of crop bacterial microbiota were caused by sub networks of hubs and their cohort partners. A singular hub pattern for oilseed rape was found in our study similar to a previous study [29]. Unlike this recent study [29], unclassified Chloroflexi of group 'KD4-96' was the single hub of the oilseed rape bacterial microbiota in our study instead of Pseudoarthrobacter. Nevertheless, the direct cohort nodes found in our study overlap, namely unclassified Chloroflexi of group 'KD4-96' itself, Paenarthrobacter, and nodes with potentially similar metabolic capabilities of ammonia oxidation (i.e. Nitrosospira) [29]. Since this cohort subnetwork appears to be reproducible across two studies, it can be considered as a functional trait specific of the oilseed rape microbiome. This assemblage may aid future research to further characterize and harness crop specific rhizosphere microbiota.

We identified Massilia as a network hub in cereal core microbiota with a high frequency to form distinct associations among host plants. The importance of Massilia for the wheat and barley rhizosphere core bacterial microbiota has only recently been recognized [16]. The recovery of Massilia as an active microbiome member over several growth stages in our study supports the classification by a previous study that it is stable member of a rhizosphere guild with the ability to upregulate carbohydrate-active enzymes in response to rhizodeposits [56]. Concerning a rye microbiota-specific differential association of Massilia with Opitutus was found, which are known as degraders of xylan [56]. Such specific differential associations might indicate distinct usage of plant-derived compounds between the crop host species. However, our observations conflict with Massilia being considered as a transient member being only present at early growth stages $[62,64]$.

We determined unclassified Tepidisphaeraceae of the group 'WD2101 soil group' as a hub of barley and the most frequent and differentially associated node, forming majorly negative associations. It most likely interacted with Nocardiodedes and uncultured Beijerinckiaceae 'alphaI cluster' within rye and wheat hosts or with Skermanella and other genera of the Actinobacteria, such as Cellulomonas, within oilseed rape and barley. This implies a competitive role within the bacterial microbiota. Bacteria similar to 'WD21-01 soil group' possess organelle-like micro compartments specialized to decomposing sugars from plant cell walls [65]. These organelles are considered to be a crucial genomic trait of plant host-specific and heritable bacterial microbiota [57]. This, supports our assumption that 'WD21-01 soil group' was most likely involved with degradation of plant cell wall components.

Consequently, the examination of hubs and their cohort partners provided reproducible information to establish a comprehensive understanding on how the rhizosphere microbiome assembly differs among crop 
species. These findings may guide culture-based physiological and single cell approaches to resolve the nature of their specific interactions.

\section{Differential associations of broadly-affiliated Bacteria facilitate understanding of their plant-host specific role} Bradyrhizobium was a biomarker taxon of wheat and oilseed in our study. This genus is considered to be enriched by other crops such as oilseed rape and to vary across soils, too [16, 58, 59, 66]. We found Bradyrhizobium to be significantly differentially associated when comparing microbial co-occurrence within wheat and oilseed rape rhizosphere, and thus suggesting different functionalities. Besides Bradyrhizobium species capable of symbiotic $\mathrm{N}_{2}$ fixation, a generalist role within the rhizosphere is implied by the unspecific transcriptomic response of Bradyrhizobium to rhizodeposits [56, 67]. Thus, we assume a distinct functional role of Bradyrhizobium within the wheat and oilseed rape microbiome.

Nocardioides belonged to the top five differential associated nodes and participated within the hub cohort of wheat and barley, representing a biomarker taxon of the latter. Thus, it was presumably key to the orchestration of both rhizosphere bacterial microbiota, but likely promoted different microbial interactions. This might have been its antifungal activities $[42,68]$.

Thus, differential associations were not only resolving the role of similar hub Bacteria in different host crops, they also explain ambiguous assignment of core biomarker taxa (LEfSe) to more than one crop species. Consequently, host-specific rhizosphere microbiota assembly is not restricted to individual bacterial genera and is determined by the interactions of keystone Bacteria.

\section{Conclusions}

Previous studies based on DNA analyses that considered the relevance of differentially abundant taxa and co-occurrence networks inferred single bacterial taxa for the plant microbiome interaction $[10,15,30]$. Our study focused on the metabolically active fractions of the bacterial microbiota (i.e. SSU RNA pool) which is more relevant as a target of green biotechnology exploiting native microbiomes for crop production [5]. We specified the extent of host plant species and family effect on bacterial microbiota structure in the rhizosphere while including two rhizosphere compartments of four common crop species belonging to Poaceae and Brassicaceae. A significant effect of host species and plant growth stages on the active bacterial microbiota was observed.

Further, we identified co-occurrence network hubs and examined their cohort partners. We highlight that these sub-networks have a superior role in core microbiota assembly and promote divergence to specific crop rhizosphere microbiomes. Hubs considered as keystone Bacteria that also had a potential role in rhizosphere guilds were among others (a) Massilia in barley and wheat, and (b) unclassified Chloroflexi of group 'KD496 ' in the oilseed rape bacterial microbiota. Differential associations between the co-occurrence networks of the core bacterial rhizosphere microbiota revealed decisive insights into their structural similarities and differences between crop species. Among them, the distinct association of 'WD21-01 soil group' with various actinobacterial genera. Thus, the study provides a blueprint of interdependent active keystone Bacteria that are capable to establish in the microbiomes of crop species over vegetative and reproductive growth stages. We conclude that instead of singularly enriched Bacteria their associations in sub-networks imposed the plant host-specific signatures within the bacterial rhizosphere microbiota. Considering theses assemblages, will be essential to future approaches that aim to modulate and harness native crop microbiomes.

\section{Supplementary Information}

The online version contains supplementary material available at https://doi. org/10.1186/s40793-021-00387-w.

Additional file 1. Bacterial composition of the core microbiota.

\section{Acknowledgements}

We thank Dr. Gernot Verch for his support of the experimental work by collecting the planting soil from the field site. Further, we acknowledge the laboratory organisation by Paul Reim and his support during soil preparation. Finally, we would like to thank Susanne Schulz and Sonja Wende for their help in maintenance of the computational facilities.

\section{Authors' contributions}

SK, UA and SL conceptualized the study. SL carried out the plant growth experiment and laboratory work. DF organized the sequencing analyses. SL supported by DF conducted data analyses. Data interpretation was performed by SL. SL wrote the first draft of the manuscript, which was reviewed by all co-authors. All authors read and approved the final manuscript.

\section{Funding}

Open Access funding enabled and organized by Projekt DEAL. The study was funded by a competitive in house funding program of the Leibniz Centre for Agricultural Landscape Research (ZALF; project identifier NMicro).

\section{Availability of data and materials}

The datasets generated and analysed during the current study are available in the NCBI sequence database under accession PRJNA746551.

\section{Declarations}

Ethics approval and consent to participate Not applicable.

Consent for publication

Not applicable.

Competing interests

The authors declare that they have no competing interests. 


\section{Author details}

${ }^{1}$ Microbial Biogeochemistry, Research Area Landscape Functioning, Leibniz Centre for Agricultural Landscape Research e.V. (ZALF), Müncheberg, Germany. ${ }^{2}$ Thaer Institute, Faculty of Life Sciences, Humboldt University of Berlin, Berlin, Germany.

Received: 10 August 2021 Accepted: 28 September 2021 Published online: 12 October 2021

\section{References}

1. Vandenkoornhuyse P, Quaiser A, Duhamel M, Le Van A, Dufresne A. The importance of the microbiome of the plant holobiont. New Phytol. 2015;206:1196-206. https://doi.org/10.1111/nph.13312.

2. Hassani MA, Durán P, Hacquard S. Microbial interactions within the plant holobiont. Microbiome. 2018;6:58. https://doi.org/10.1186/ s40168-018-0445-0.

3. Philippot L, Raaijmakers JM, Lemanceau P, Van Der Putten WH. Going back to the roots: the microbial ecology of the rhizosphere. Nat Rev Microbiol. 2013;11:789-99. https://doi.org/10.1038/nrmicro3109.

4. Toju H, Peay KG, Yamamichi M, Narisawa K, Hiruma K, Naito K, et al. Core microbiomes for sustainable agroecosystems. Nat Plants. 2018;4:247-57. https://doi.org/10.1038/s41477-018-0139-4.

5. Trivedi P, Mattupalli C, Eversole K, Leach JE. Enabling sustainable agriculture through understanding and enhancement of microbiomes. New Phytol. 2021;230:2129-47. https://doi.org/10.1111/nph.17319.

6. Erisman JW, Sutton MA, Galloway J, Klimont Z, Winiwarter W. How a century of ammonia synthesis changed the world. Nat Geosci. 2008;1:636-9. https://doi.org/10.1038/ngeo325.

7. Smith P, House Jl, Bustamante M, Sobocká J, Harper R, Pan G, et al. Global change pressures on soils from land use and management. Glob Chang Biol. 2016;22:1008-28. https://doi.org/10.1111/gcb.13068.

8. Lugtenberg B, Kamilova F. Plant-growth-promoting rhizobacteria. Annu Rev Microbiol. 2009;63:541-56. https://doi.org/10.1146/annurev.micro.62. 081307.162918

9. Backer R, Rokem JS, llangumaran G, Lamont J, Praslickova D, Ricci E, et al. Plant growth-promoting rhizobacteria: context, mechanisms of action, and roadmap to commercialization of biostimulants for sustainable agriculture. Front Plant Sci. 2018;9:1473. https://doi.org/10.3389/fpls.2018. 01473.

10. Bulgarelli D, Schlaeppi K, Spaepen S, van Themaat EVL, Schulze-Lefert P. Structure and functions of the bacterial microbiota of plants. Annu Rev Plant Biol. 2013;64:807-38. https://doi.org/10.1146/annurev-arpla nt-050312-120106.

11. Jones DL, Nguyen C, Finlay RD. Carbon flow in the rhizosphere: carbon trading at the soil-root interface. Plant Soil. 2009;321:5-33. https://doi. org/10.1007/s11104-009-9925-0.

12. Kuzyakov $Y, X u X$. Competition between roots and microorganisms for nitrogen: mechanisms and ecological relevance. New Phytol. 2013;198:656-69. https://doi.org/10.1111/nph.12235.

13. Bulgarelli D, Rott M, Schlaeppi K, Ver Loren van Themaat E, Ahmadinejad $\mathrm{N}$, Assenza F, et al. Revealing structure and assembly cues for Arabidopsis root-inhabiting bacterial microbiota. Nature. 2012;488:91-5. doi:https:// doi.org/10.1038/nature11336.

14. Lundberg DS, Lebeis SL, Paredes SH, Yourstone S, Gehring J, Malfatti S, et al. Defining the core Arabidopsis thaliana root microbiome. Nature. 2012:488:86-90. https://doi.org/10.1038/nature11237.

15. Bulgarelli D, Garrido-Oter R, Münch PC, Weiman A, Dröge J, Pan Y, et al. Structure and function of the bacterial root microbiota in wild and domesticated barley. Cell Host Microbe. 2015;17:392-403. https://doi.org/ 10.1016/J.CHOM.2015.01.011.

16. Schlatter DC, Yin C, Hulbert S, Paulitz TC. Core Rhizosphere Microbiomes of Dryland Wheat Are Influenced by Location and Land Use History. Appl Environ Microbiol. 2020;86:e02135-e2219. https://doi.org/10.1128/AEM. 02135-19.

17. Simonin M, Dasilva C, Terzi V, Ngonkeu ELM, Diouf D, Kane A, et al. Influence of plant genotype and soil on the wheat rhizosphere microbiome: evidences for a core microbiome across eight African and European soils. FEMS Microbiol Ecol. 2020;96. doi:https://doi.org/10.1093/femsec/fiaa067.
18. Vieira S, Sikorski J, Dietz S, Herz K, Schrumpf M, Bruelheide H, et al. Drivers of the composition of active rhizosphere bacterial communities in temperate grasslands. ISME J. 2020;14:463-75. https://doi.org/10.1038/ s41396-019-0543-4

19. Yeoh YK, Paungfoo-Lonhienne C, Dennis PG, Robinson N, Ragan MA, Schmidt S, et al. The core root microbiome of sugarcanes cultivated under varying nitrogen fertilizer application. Environ Microbiol. 2016;18:1338-51. https://doi.org/10.1111/1462-2920.12925.

20. Hamonts K, Trivedi P, Garg A, Janitz C, Grinyer J, Holford P, et al. Field study reveals core plant microbiota and relative importance of their drivers. Environ Microbiol. 2018;20:124-40. https://doi.org/10.1111/1462-2920. 14031.

21. Gkarmiri K, Mahmood S, Ekblad A, Alström S, Högberg N, Finlay R. Identifying the active microbiome associated with roots and rhizosphere soil of oilseed rape. Appl Environ Microbiol. 2017;83:e01938-e2017. https://doi. org/10.1128/AEM.01938-17.

22. Tkacz A, Pini F, Turner TR, Bestion E, Simmonds J, Howell P, et al. Agricultural selection of wheat has been shaped by plant-microbe interactions. Front Microbiol. 2020;11:132. https://doi.org/10.3389/fmicb.2020.00132.

23. Rascovan N, Carbonetto B, Perrig D, Díaz M, Canciani W, Abalo M, et al. Integrated analysis of root microbiomes of soybean and wheat from agricultural fields. Sci Rep. 2016;6:1-12. https://doi.org/10.1038/srep28084.

24. Turner TR, Ramakrishnan K, Walshaw J, Heavens D, Alston M, Swarbreck D, et al. Comparative metatranscriptomics reveals kingdom level changes in the rhizosphere microbiome of plants. ISME J. 2013;7:2248-58. https:// doi.org/10.1038/ismej.2013.119.

25. Ofek-Lalzar M, Sela N, Goldman-Voronov M, Green SJ, Hadar Y, Minz D. Niche and host-associated functional signatures of the root surface microbiome. Nat Commun. 2014;5:4950. https://doi.org/10.1038/ncomm s5950.

26. Wink M. Evolution of secondary metabolites from an ecological and molecular phylogenetic perspective. Phytochemistry. 2003;64:3-19. https://doi.org/10.1016/S0031-9422(03)00300-5.

27. Schlatter DC, Hansen JC, Schillinger WF, Sullivan TS, Paulitz TC. Common and unique rhizosphere microbial communities of wheat and canola in a semiarid mediterranean environment. Appl Soil Ecol. 2019;144:170-81. https://doi.org/10.1016/j.apsoil.2019.07.010.

28. Oberholster T, Vikram S, Cowan D, Valverde A. Key microbial taxa in the rhizosphere of sorghum and sunflower grown in crop rotation. Sci Total Environ. 2018;624:530-9. https://doi.org/10.1016/J.SCITOTENV.2017.12. 170.

29. Floc'h J-B, Hamel C, Lupwayi N, Harker KN, Hijri M, St-Arnaud M. Bacterial communities of the canola rhizosphere: Network analysis reveals a core bacterium shaping microbial interactions. Front Microbiol. 2020;11:1587. doi:https://doi.org/10.3389/fmicb.2020.01587.

30. Xiong C, Zhu Y, Wang J, Singh B, Han L, Shen J, et al. Host selection shapes crop microbiome assembly and network complexity. New Phytol. 2021;229:1091-104. https://doi.org/10.1111/nph.16890.

31. Segata N, Izard J, Waldron L, Gevers D, Miropolsky L, Garrett WS, et al. Metagenomic biomarker discovery and explanation. Genome Biol. 2011;12:R60. https://doi.org/10.1186/gb-2011-12-6-r60.

32. Banerjee $S$, Schlaeppi K, van der Heijden MGA. Keystone taxa as drivers of microbiome structure and functioning. Nat Rev Microbiol. 2018;16:56776. https://doi.org/10.1038/s41579-018-0024-1.

33. Shade A, Stopnisek N. Abundance-occupancy distributions to prioritize plant core microbiome membership. Curr Opin Microbiol. 2019;49:50-8. https://doi.org/10.1016/j.mib.2019.09.008.

34. Donn S, Kirkegaard JA, Perera G, Richardson AE, Watt M. Evolution of bacterial communities in the wheat crop rhizosphere. Environ Microbiol. 2015;17:610-21. https://doi.org/10.1111/1462-2920.12452.

35. Blazewicz SJ, Barnard RL, Daly RA, Firestone MK. Evaluating rRNA as an indicator of microbial activity in environmental communities: limitations and uses. ISME J. 2013;7:2061-8. https://doi.org/10.1038/ismej.2013.102.

36. Apprill A, McNally S, Parsons R, Weber L. Minor revision to V4 region SSU rRNA 806R gene primer greatly increases detection of SAR11 bacterioplankton. Aquat Microb Ecol. 2015;75:129-37. https://doi.org/10.3354/ ame01753.

37. Francioli D, Lentendu G, Lewin S, Kolb S. DNA metabarcoding for the characterization of terrestrial microbiota-pitfalls and solutions. Microorganisms. 2021;9:361. https://doi.org/10.3390/microorganisms9020361. 
38. Bolyen E, Rideout JR, Dillon MR, Bokulich NA, Abnet CC, Al-Ghalith GA, et al. Reproducible, interactive, scalable and extensible microbiome data science using QIIME 2. Nat Biotechnol. 2019;37:852-7. https://doi.org/10. 1038/s41587-019-0209-9.

39. Callahan BJ, McMurdie PJ, Rosen MJ, Han AW, Johnson AJA, Holmes SP. DADA2: high-resolution sample inference from Illumina amplicon data. Nat Methods. 2016;13:581-3. https://doi.org/10.1038/nmeth.3869.

40. Quast C, Pruesse E, Yilmaz P, Gerken J, Schweer T, Yarza P, et al. The SILVA ribosomal RNA gene database project: improved data processing and web-based tools. Nucleic Acids Res. 2012;41:D590-6. https://doi.org/10. 1093/nar/gks1219.

41. Bokulich NA, Kaehler BD, Rideout JR, Dillon M, Bolyen E, Knight R, et al. Optimizing taxonomic classification of marker-gene amplicon sequences with QIIME 2's q2-feature-classifier plugin. Microbiome. 2018;6:90. https:// doi.org/10.1186/s40168-018-0470-z.

42. Ikunaga Y, Sato I, Grond S, Numaziri N, Yoshida S, Yamaya H, et al. Nocardioides sp. strain WSN05-2, isolated from a wheat field, degrades deoxynivalenol, producing the novel intermediate 3-epi-deoxynivalenol. Appl Microbiol Biotechnol. 2011;89:419-27. doi:https://doi.org/10.1007/ s00253-010-2857-z.

43. R Core Team. R: a language and environment for statistical computing. Vienna: R Foundation for statistical Computing; 2020

44. RStudio Team. RStudio: integrated development environment for R. RStudio, Inc; 2019. http://www.rstudio.com/.

45. McMurdie PJ, Holmes S. phyloseq: An R package for reproducible interactive analysis and graphics of microbiome census data. PLOS ONE. 2013;8: e61217. https://doi.org/10.1371/journal.pone.0061217.

46. Wickham H. ggplot2: Elegant graphics for data analysis. Springer-Verlag New York; 2016. https://ggplot2.tidyverse.org.

47. Gu Z, Gu L, Eils R, Schlesner M, Brors B. circlize implements and enhances circular visualization in R. Bioinformatics. 2014;30:2811-2.

48. Oksanen J, Blanchet FG, Friendly M, Kindt R, Legendre P, McGlinn D, et al. vegan: Community ecology package. 2019. https://cran.r-project.org/ package $=$ vegan .

49. Jari O, Blanchet FG, Friendly M, Roeland K, Legendre P, Minchin PR, et al. R package version 2.5-6. Vegan: Community Ecology Package; 2019

50. Yoon G, Müller CL, Gaynanova I. Fast computation of latent correlations. J Comput Graph Stat. 2020. http://arxiv.org/abs/2006.13875. Accessed 24 Jun 2021.

51. Peschel $\mathrm{S}$, Müller CL, von Mutius E, Boulesteix A-L, Depner M. NetCoMi: network construction and comparison for microbiome data in R. Brief Bioinform. 2020. https://doi.org/10.1093/bib/bbaa290.

52. Siska C, Kechris K. discordant: The discordant method: A novel approach for differential correlation. 2020. https://github.com/siskac/discordant.

53. Emmett BD, Youngblut ND, Buckley DH, Drinkwater LE. Plant Phylogeny and life history shape rhizosphere bacterial microbiome of summer annuals in an agricultural field. Front Microbiol. 2017;8:2414. https://doi. org/10.3389/fmicb.2017.02414.

54. Péret B, Desnos T, Jost R, Kanno S, Berkowitz O, Nussaume L. Root architecture responses in search of phosphate. Plant Physiol. 2014;166:171323. https://doi.org/10.1104/pp.114.244541.

55. Hansen JC, Schillinger WF, Sullivan TS, Paulitz TC. Rhizosphere microbial communities of canola and wheat at six paired field sites. Appl Soil Ecol. 2018;130:185-93. https://doi.org/10.1016/J.APSOIL.2018.06.012.
56. O'Brien FJM, Dumont MG, Webb JS, Poppy GM. Rhizosphere bacterial communities differ according to fertilizer regimes and cabbage (Brassica oleracea var. capitata l.) harvest time, but not aphid herbivory. Front Microbiol. 2018;9 JUL:1620.

57. Nuccio EE, Starr E, Karaoz U, Brodie EL, Zhou J, Tringe SG, et al. Niche differentiation is spatially and temporally regulated in the rhizosphere. ISME J. 2020;14:999-1014. https://doi.org/10.1038/s41396-019-0582-x.

58. Deng S, Caddell DF, Xu G, Dahlen L, Washington L, Yang J, et al. Genome wide association study reveals plant loci controlling heritability of the rhizosphere microbiome. ISME J. 2021; 1-14. doi:https://doi.org/10.1038/ s41396-021-00993-z.

59. Matthews A, Pierce S, Hipperson H, Raymond B. Rhizobacterial community assembly patterns vary between crop species. Front Microbiol. 2019;10 April:1-13. doi:https://doi.org/10.3389/fmicb.2019.00581.

60. Haichar FEZ, Marol C, Berge O, Rangel-Castro JI, Prosser JI, Balesdent J, et al. Plant host habitat and root exudates shape soil bacterial community structure. ISME J. 2008;2:1221-30. https://doi.org/10.1038/ismej.2008. 80.

61. Prudence SM, Newittt JT, Worsley SF, Macey MC, Murrell JC, LehtovirtaMorley LE, et al. Soil, senescence and exudate utilisation: characterisation of the Paragon var. spring bread wheat root microbiome. Environ Microbiome. 2021;16:12. doi:https://doi.org/10.1186/s40793-021-00381-2.

62. Zhang R, Vivanco JM, Shen Q. The unseen rhizosphere root-soil-microbe interactions for crop production. Curr Opin Microbiol. 2017;37:8-14. https://doi.org/10.1016/j.mib.2017.03.008.

63. Emmett BD, Buckley DH, Drinkwater LE. Plant growth rate and nitrogen uptake shape rhizosphere bacterial community composition and activity in an agricultural field. New Phytol. 2020;225:960-73. https://doi.org/10. 1111/nph.16171.

64. Lemanceau P, Blouin M, Muller D, Moënne-Loccoz Y. Let the core microbiota be functional. Trends Plant Sci. 2017;22:583-95. https://doi.org/10. 1016/j.tplants.2017.04.008.

65. Ofek M, Hadar Y, Minz D. Ecology of root colonizing Massilia (Oxalobacteraceae). PLOS ONE. 2012;7:e40117. https://doi.org/10.1371/journal.pone. 0040117.

66. Dedysh SN, Beletsky AV, Ivanova AA, Kulichevskaya IS, Suzina NE, Philippov DA, et al. Wide distribution of Phycisphaera-like Planctomycetes from WD2101 soil group in peatlands and genome analysis of the first cultivated representative. Environ Microbiol. 2021;23:1510-26. https://doi. org/10.1111/1462-2920.15360.

67. Hilton S, Bennett AJ, Chandler D, Mills P, Bending GD. Preceding crop and seasonal effects influence fungal, bacterial and nematode diversity in wheat and oilseed rape rhizosphere and soil. Appl Soil Ecol. 2018;126:3446. https://doi.org/10.1016/J.APSOIL.2018.02.007.

68. Chaparro JM, Badri DV, Vivanco JM. Rhizosphere microbiome assemblage is affected by plant development. ISME J. 2014;8:790-803. https://doi.org/ 10.1038/ismej.2013.196.

\section{Publisher's Note}

Springer Nature remains neutral with regard to jurisdictional claims in published maps and institutional affiliations.

Ready to submit your research? Choose BMC and benefit from:

- fast, convenient online submission

- thorough peer review by experienced researchers in your field

- rapid publication on acceptance

- support for research data, including large and complex data types

- gold Open Access which fosters wider collaboration and increased citations

- maximum visibility for your research: over $100 \mathrm{M}$ website views per year

At BMC, research is always in progress.

Learn more biomedcentral.com/submissions 